\title{
INCREASING PRODUCTIVITY BY USING A MIXER TRANSPORT UNIT FOR LOADING SPRAYERS
}

\author{
Krasimir Trendafilov \\ Trakia University, Faculty of Technics and Technologies \\ 38, Graf Ignatiev Str., Yambol, 8600, Bulgaria, e-mail: trendafilov@outlook.com
}

\begin{abstract}
Spraying of plants against diseases and pests should be carried out within a short time. One way to increase the performance of sprayers is by reducing the unproductive spray time. For this purpose, a transport mixing unit is available on the market, which reduces the preparation time of the working solution. This unit and the benefits of using it are not well known to many farmers. Existing research shows that its use results in a double increase in productivity compared to transporting water from the sprayer itself. This article proposes a methodology for determining the variation in sprayer performance when loaded with a working solution by transport mixing unit compared to loading it with water by an ordinary tank with the same parameters. Analytical dependencies have been generated for determining the duration of individual operations during operation of the sprayer and mixing unit, as well as for calculating the percentage increase in the productivity of the sprayer. The methodology has been demonstrated for specific sprayers and mixers under specific conditions. In this case, it was found that filling the sprayer with a solution instead of pure water could increase its productivity by $34.5 \%$.
\end{abstract}

Keywords: mixing transport unit, sprayer, performance, spray solution.

\section{INTRODUCTION}

Chemical protection of plants from diseases and pests and weed control is carried out through the introduction of pesticides using sprayers. Typically, the solution of the respective preparation is prepared in the sprayers themselves, for which purpose they are equipped with mixing vessels (at a larger volume of the tank) or with mesh mixers placed in the reservoir neck. Stirring of the solution to achieve and maintain a constant concentration is carried out by means of various types of stirrers. For good stirring it usually takes about 1015 minutes. Loading the sprayer's tank with water can be done by their own pump or by other water tank. The water charging time depends on the flow rate of the pump being used - on the sprayer or on the water tank.

A mixing transport unit (Figure 1) is produced in Russia, which is intended for the preparation of the spraying solution, transporting it to the field and charging the sprayers [3]. The machine consists of a large volume tank $\left(5\right.$ or $\left.11 \mathrm{~m}^{3}\right)$, a tank for placing the pesticide and a high-flow pump (1000 l/min). With this machine, the spray solution is prepared and loaded into the sprayer tank, saving time and increasing sprayer performance. In addition, a constant solution concentration is maintained which is more difficult to achieve when the sprayer is loaded with water only in the field and subsequent solution preparation since in this case a portion of the solution is left in the tank after the last working move. When using a mixing unit, the number of spraying machines can be reduced by 1.5 times according to some authors [1]. According to others, using the same mixing unit with a tank volume of $5 \mathrm{~m}^{3}$ the productivity is increased by about 2 times compared to the transport of water with the sprayer itself [2]. 


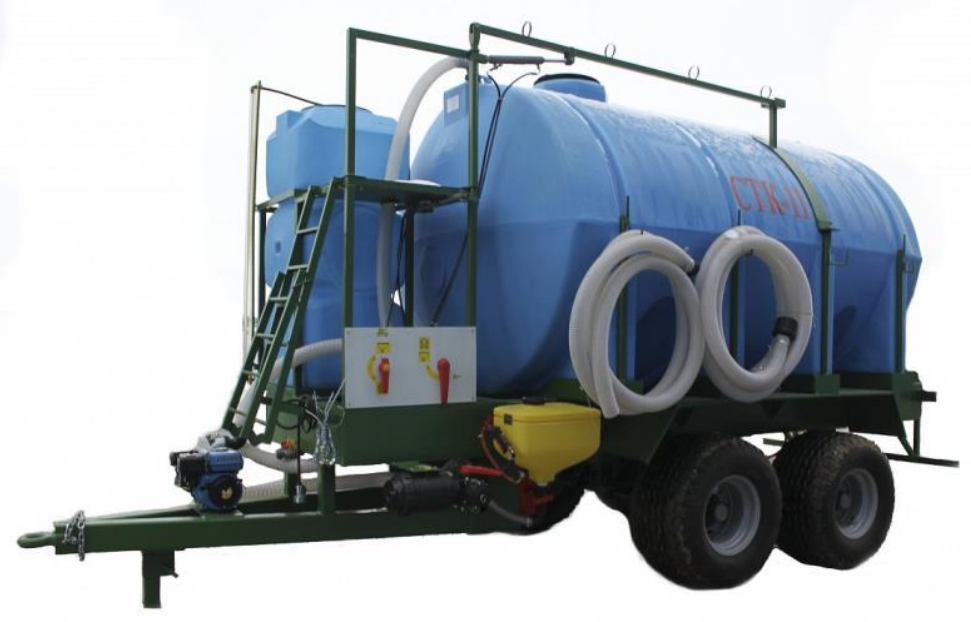

Figure 1. Mixing transport unit

Such a mixing unit is not used in our country because it is still unknown to the farmers. The advantages described by the manufacturers and some researchers raise the question the extent to which the use of a tank combined with a mixer for the preparation of the spray solution will result in an increase in sprayer performance in comparison with sprayers refill with water from an ordinary tank.

The objective of this work is to determine how the use of a mixing transport unit to prepare and transport the solution to the field affects the performance of the sprayers.

\section{MATERIAL AND METHOD}

An analytical method is used to determine the parameters of the working process. Dependencies have been drawn to determine the duration of the individual operations during the working process of the sprayer and the mixing transport unit. The duration of the sprayer cycle and the mixer cycle are determined. A comparison is made between the performance of the sprayer when charging it with water and charging it with a mixer-prepared solution. It is assumed that charging is done under the same conditions - tank volume and pump flow. An example is given with specific parameters of the working machines on the basis of which the corresponding conclusions are made.

\section{RESULTS AND DISCUSSION}

The performance of the sprayer is determined by the dependence

$$
W=B \cdot v \cdot \tau, \mathrm{da} / \mathrm{h}
$$

where $B$ is the working width of the sprayer (wing length), $\mathrm{m}$;

$v$ - the working speed, $\mathrm{km} / \mathrm{h}$;

$T$ - the coefficient of utilization of working time.

The coefficient of utilization of the working time is a ratio between pure working time (operating time) and total time for one working shift:

$$
\tau=\frac{T_{W}}{T_{T}}
$$

IRTIIE Vol. 7, No. 3, 2019 ISSN 1314-8788 (print), ISSN 1314-8796 (online), doi: 10.15547/artte.2019.03.001 


\section{ARTIL

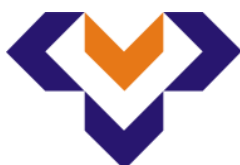 \\ Ipplied Researroches in Technics, Technologies and Buncition \\ Journal of the Faculty of Technics and Technologies, Trakia University https:///ites.google.com/a/trakia-uni.bg/artte/}

where $T_{W}$ is the pure working time for one working shift, $\mathrm{h}$;

$T_{T}$ - the total time for one working shift, $\mathrm{h}$.

The total time for one working shift is

$$
T_{T}=T_{C} \cdot N_{C}+t_{R}+t_{D}=\left(t_{W}+t_{N}+t_{C W}+t_{C P}\right) N_{C}+t_{R}+t_{D}, \quad \mathrm{~h}
$$

where $T_{C}$ is the duration of one working cycle of the sprayer, $\mathrm{h}$;

$N_{C}$ - the number of working cycles per one working shift;

$t_{W}$ - the pure working time of one cycle, $\mathrm{h}$;

$t_{N}$ - the time for carrying out non-working moves (turns) within one cycle, $\mathrm{h}$;

$t_{C W}$ - the charging time with water of one sprayer tank, $\mathrm{h}$;

$t_{C P}$ - the charging time with pesticide and mixing, $\mathrm{h}$;

$t_{R}$ - the time for rest during the shift, $\mathrm{h}$;

$t_{D}$ - the time lost for different reasons, during which the sprayer does not work, for example, due to awaiting the arrival of the tank to the field.

The number of working cycles, which carried out the sprayer for one shift, is

$$
N_{C}=\frac{T_{W S}}{T_{C}}, \quad \mathrm{~h}
$$

where $T_{W S}$ is the duration of working time during the shift without breaks. In spraying the total length of the working shift is 7 hours.

The result obtained in (4) must be rounded to the lower integer in order not to exceed the maximum permissible operating time with preparations, which is $6 \mathrm{~h}$.

Using the dependency (3), the coefficient of utilization of working time can be presented in the following way

$$
\tau=\frac{t_{W} \cdot N_{C}}{T_{C} \cdot N_{C}+t_{R}+t_{D}}, \quad \mathrm{~h}
$$

When the sprayer is charged from a tank with clean water and a pesticide is placed in it separately, its performance is determined by the dependence

$$
W_{0}=B \cdot v \cdot \frac{t_{W} \cdot N_{C}}{\left(t_{W}+t_{N}+t_{C W}+t_{C P}\right) N_{C}+t_{R}+t_{D}}, \quad \mathrm{da} / \mathrm{h}
$$

In the case that the tank has a mixer and the solution is prepared in advance, i.e. when using the unit shown in Fig. 1, the sprayer performance is

$$
W_{1}=B \cdot v \cdot \frac{t_{W} \cdot N_{C}}{\left(t_{W}+t_{N}+t_{C W}\right) N_{C}+t_{R}+t_{D}}, \quad \mathrm{da} / \mathrm{h}
$$

as there is no time to prepare the solution.

The relative increase in sprayer productivity using a mixing transport unit to prepare the solution compared to preparing the solution in the sprayer itself is

$$
W_{\%}=\frac{W_{1}-W_{0}}{W_{0}} \cdot 100=\frac{t_{C P .} N_{C}}{\left(t_{W}+t_{N}+t_{C W}\right) N_{C}+t_{R}+t_{D}} \cdot 100, \%
$$

The times in the last formula are determined in the following way. 


\section{AR'IIL Ipplied Researroches in Technics, Technologies and Buncition Journal of the Faculty of Technics and Technologies, Trakia University https:///ites.google.com/a/trakia-uni.bg/artte/}

\subsection{Time for carrying out working moves}

It is determined by the dependency

$$
t_{W}=\frac{n_{w} \cdot l_{w}}{1000 \cdot v}, \quad \mathrm{~h}
$$

where $n_{w}$ is the number of work moves carried out with one tank volume;

$l_{w}$ - the length of a work move, $\mathrm{m}$.

The length of one work move when spraying perennial crops is equal to the length of the row, and when spraying field crops it is [4]

$$
l_{w}=L_{f}-2 E=L_{f}-2 B, \quad \mathrm{~m}
$$

where $L_{f}$ is the length of the field, $\mathrm{m}$;

$E$ - the width of the headland (usually equal to the working width of the sprayer), $\mathrm{m}$. The area that is sprayed with one tank of the sprayer is calculated by the dependence

$$
S=\frac{V_{S}}{D}, \quad \text { ha }
$$

where $V_{S}$ is the volume of the tank of the sprayer, $\mathrm{dm}^{3}$;

$D$ - the expenditure rate of solution, $\mathrm{l} / \mathrm{ha}$.

From here, the number of work moves that will make the sprayer until its next charging is

$$
n_{w}=\frac{1000 \cdot S}{l_{w} \cdot B} .
$$

The result obtained must be rounded to the lower integer. The expenditure rate of the solution should be selected so that the number of working moves is an even number. In this way, the sprayer will only be charged on one side of the field and one mixing unit is required. The expenditure rate of the solution to fulfill this condition can be determined by the dependence

$$
D_{n}=\frac{10000 \cdot V_{S}}{n_{w} \cdot l_{w} \cdot B}, \mathrm{l} / \mathrm{ha}
$$

where $D_{n}$ is the required expenditure rate of a solution to carry out an even number of working moves with one sprayer tank, I/ha. A new expenditure rate is chosen that is smaller than the resulting one, i.e. adjusted expenditure rate $D_{k}$ in $1 /$ ha.

\subsection{Time for carrying out non-working moves (turns)}

The number of non-working moves is with1 less than the number of working moves when the work moves are an even number, i.e.

$$
n_{n}=n_{w}-1
$$

The time for making non-working moves for one working cycle of the sprayer is

$$
t_{N}=\frac{n_{n} \cdot l_{n}}{1000 \cdot v_{n}}=\frac{\left(n_{w}-1\right) l_{n}}{1000 \cdot v_{n}}, \mathrm{~h}
$$

IRTIIE Vol. 7, No. 3, 2019 ISSN 1314-8788 (print), ISSN 1314-8796 (online), doi: 10.15547/artte.2019.03.001 


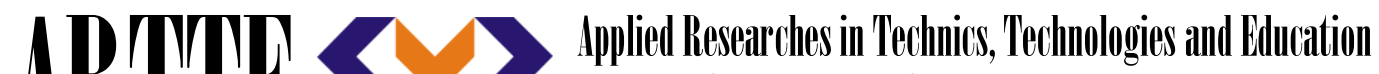 Journal of the Faculty of Technics and Technologies, Trakia University https://sites.google.com/a/trakia-uni.bg/artte/}

where $l_{n}$ is the length of a non-working move, $\mathrm{m}$;

$v_{n}$ - the speed of the sprayer during the non-working moves, $\mathrm{km} / \mathrm{h}$.

The sprayers usually carried out shuttle moves into the field and at the end of the field they make oblong turns with length depending on the type of sprayer (for perennial crops or for field crops), the working width and the possible minimum turning radius of the unit. Pearshaped turns are virtually inaccessible, as they require a larger width of the headland, which is particularly limited in perennial plantations. Pear-shaped turns are avoided as working moves are carried out through one or several rows and the sprayer moves overlapping the work moves. The length of the non-working moves (turns) in which the sprayer is off is determined with the following dependencies:

- for boom sprayers - oblong turn

$$
l_{n}=2 B-0.86 R, \quad \mathrm{~m}
$$

where $R$ is the radius of the turn of the unit, $m$

- for fan sprayers in perennial plantations - oblong turn [4]

$$
l_{n}=2.14 R+X+2 l_{k}, \quad \mathrm{~m}
$$

where $X$ is the distance between consecutive working moves (it is multiple of the width of the row), $\mathrm{m}$;

$l_{k}$ - the kinematic length of the unit (the distance from the rear axle of the tractor to the spray nozzles), $\mathrm{m}$.

\subsection{Time for charging sprayer tank}

In the tank of the sprayer will always remain a certain amount of solution before the next charging

$$
Q_{r}=V_{s}-Q_{c}, \text { I }
$$

where $Q_{r}$ is the remaining amount solution in the sprayer tank, I;

$Q_{c}$ - the amount of solution consumed in the working moves, I. It is determined by the dependence

$$
Q_{c}=\frac{n_{w} \cdot l_{w} \cdot B \cdot D_{k}}{10000}, \text { । }
$$

This amount of solution should be added to the sprayer tank from the mixing transport unit. The time for which the fill is performed is

$$
t_{C W}=\frac{Q_{c}}{60 . q_{m u}}, \mathrm{~h}
$$

where $q_{m u}$ is the flow rate of the pump of the mixer unit, $1 / \mathrm{min}$.

\subsection{Time for charging with pesticide and mixing}

The time for placing the pesticide in the mixing tank of the sprayer and mixing until a homogeneous solution is obtained before spraying starts depends on the type of preparation and volume of the sprayer tank, but is usually no more than $t_{C P}=10-15 \mathrm{~min}$.

IRTIIE Vol. 7, No. 3, 2019 ISSN 1314-8788 (print), ISSN 1314-8796 (online), doi: 10.15547/artte.2019.03.001 


\section{AR'IIL Ipplied Researreches in Technics, Technologies and Bdurition Journal of the Faculty of Technics and Technologies, Trakia University https:///ites.google.com/a/trakia-uni.bg/artte/}

\subsection{Time for rest during the working shift}

The duration of the rest $t_{R}$ is regulated. Lunch breaks can not be longer than 30 minutes. Other breaks may be made during the shift. It is best if the breaks coincide with the waiting time for the arrival of the water tank to the field.

\subsection{Loss of time for different reasons}

Losses of time $t_{D}$ may occur due to a malfunction of the machine, poor organization of work, waiting of the tank with water, etc.

\subsection{Performance characteristics of the mixing transport unit}

The minimum amount of solution to be prepared in the mixer unit is determined by the dependence

$$
Q_{l}=N_{C} \cdot Q_{c}, \quad \text { I }
$$

The amount of solution $Q_{l}$ can be used to select the volume of the mixer unit. Other factors such as charging location, sprayer working cycle and mixer unit cycle, as well as the ability to load the mixer into the field, should be considered here. The number of charges of the mixer unit tank for one working shift is determined by the dependence

$$
n_{m u}=\frac{Q_{l}}{V_{m u}}
$$

where $V_{m u}$ is the volume of the mixing unit tank, $\mathrm{dm}^{3}$.

The result obtained in (22) should be rounded to the larger integer. At the start of the working shift the mixer and sprayer tanks are filled and transported full to the field. After the solution is discharged from the mixer tank, the tank is recharged with water in the field or moved to the charging place. The number of moves to the place of loading with water and pesticide is

$$
N_{m u}=n_{m u}-1
$$

since the first move is performed before the spraying began. The length of the charging cycle of the mixing unit and its transport to the field and vice versa is

$$
T_{m u}=t_{m u}+t_{t m u}, \mathrm{~h}
$$

where $t_{m u}$ is the time for loading the mixer unit tank, $\mathrm{h}$

$t_{t m u}$ - the time for the transport of the mixer unit, $\mathrm{h}$.

Loading of the tank of the mixing unit with water and pesticide is done at the same time and is determined by the dependence

$$
t_{m u}=\frac{V_{m u}}{60 . q_{m u}}, \mathrm{~h}
$$

The transport time is determined by dependence

$$
t_{t m u}=\frac{2 \cdot l_{t}}{v_{t}}, \mathrm{~h}
$$

IRTIIE Vol. 7, No. 3, 2019 ISSN 1314-8788 (print), ISSN 1314-8796 (online), doi: 10.15547/artte.2019.03.001 


\section{ARTITE

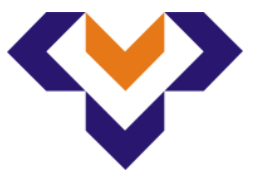

Ipplied Researroches in Technics, Technologies and Buncition

Journal of the Faculty of Technics and Technologies, Trakia University https://sites.google.com/a/trakia-uni.bg/artte/

where $l_{t}$ is the transport distance, $\mathrm{km}$;

$v_{t}$ - the transport speed of the mixer unit, $\mathrm{km} / \mathrm{h}$.

Several factors influence the performance of the sprayer and therefore it is not possible to determine unequivocally the extent of increase in productivity when using a mixing unit. This can be done on a case-by-case basis using the above dependencies. Below is an example with the following output data:

- length of field $-L_{f}=1000 \mathrm{~m}$;

- $\quad$ working width of the bar sprayer $-B=18 \mathrm{~m}$;

- volume of the tank of the sprayer $-V_{s}=1500 l$;

- $\quad$ working speed of the sprayer $-v=10 \mathrm{~km} / \mathrm{h}$;

- $\quad$ speed of the sprayer during the non-working moves $-v_{n}=8 \mathrm{~km} / \mathrm{h}$;

- $\quad$ radius of the turn of unit $-R=6 \mathrm{~m}$;

- $\quad$ expenditure rate of solution $-D=250 \mathrm{l} / \mathrm{ha}$;

- flow rate of the pump of the mixer unit $-q_{m u}=1000 \mathrm{l} / \mathrm{min}$;

- $\quad$ transport distance $-l_{t}=5 \mathrm{~km}$;

- $\quad$ transport speed of the mixer unit $-v_{t}=12 \mathrm{~km} / \mathrm{h}$;

- $\quad$ time for rest during the working shift and losses of time for different reasons $-t_{R}+t_{D}=$ $1 h$;

- $\quad$ charging time with pesticide (concentrate) and mixing $-t_{C P}=0.17 \mathrm{~h}$.

Based on these data are defined:

- length of the non-working move

$$
l_{n}=2 B-0.86 R=2.18-0,86.6=30,84 m
$$

- length of the working move

$$
l_{w}=L_{f}-2 E=L_{f}-2 B=1000-2.18=964 m
$$

- $\quad$ area sprayed with one tank of the sprayer

$$
S=\frac{V_{S}}{D}=\frac{1500}{250}=6 h a
$$

- $\quad$ number of working moves

$$
n_{w}=\frac{1000 . S}{l_{w} \cdot B}=\frac{1000.6}{964.18}=3,45 \Rightarrow 3 \text { working moves }
$$

In this case, the work moves are an odd number and a change in the expenditure rate is required. The maximum rate at which work moves will be an even number and closest to the result obtained, i.e. 4 moves is

$$
D_{n}=\frac{10000 \cdot V_{s}}{n_{w} \cdot l_{w} \cdot B}=\frac{10000.15000}{4.964 .18}=216 \mathrm{l} / \mathrm{ha}
$$

- $\quad$ selection of new expenditure rate less than the resulting $-D_{k}=200 \mathrm{l} / \mathrm{ha}$

- the area sprayed by one tank and the number of working moves are recalculated for verification

$$
S=\frac{V_{S}}{D}=\frac{1500}{200}=7,5 h a
$$

IRTIIE Vol. 7, No. 3, 2019 ISSN 1314-8788 (print), ISSN 1314-8796 (online), doi: 10.15547/artte.2019.03.001 


\section{IRTITE}

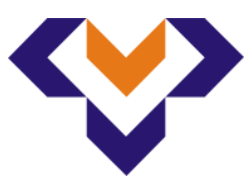

Applied Researlohes in Technics, Technologies and Bducation Journal of the Faculty of Technics and Technologies, Trakia University https://sites.google.com/a/trakia-uni.bg/artte/

$$
n_{w}=\frac{1000 . S}{l_{w} \cdot B}=\frac{1000.7,5}{964.18}=4,3 \Rightarrow 4 \text { working moves }
$$

- used amount of solution for carrying out the work moves

$$
Q_{c}=\frac{n_{w} \cdot l_{w} \cdot B \cdot D_{k}}{10000}=\frac{4.964 \cdot 18.200}{10000}=1388,16 l
$$

- time for charging sprayer tank

$$
t_{C W}=\frac{Q_{c}}{60 . q_{m u}}=\frac{1888,16}{60.1000}=0,023 \mathrm{~h}
$$

- time for carrying out working moves

$$
t_{W}=\frac{n_{w} \cdot l_{w}}{1000 . v}=\frac{4.964}{1000.10}=0,386 h,
$$

- time for carrying out non-working moves

$$
t_{N}=\frac{\left(n_{W}-1\right) l_{n}}{1000 . v_{n}}=\frac{(4-1) 30,84}{1000.8}=0,012 \mathrm{~h}
$$

- duration of one working cycle of the sprayer

$$
T_{C}=t_{W}+t_{N}+t_{C W}=0,386+0,012+0,023=0,421 \mathrm{~h}
$$

- number of cycles carried out by the sprayer for the maximum allowable operating time of 6 hours

$$
N_{C}=\frac{T_{W S}}{T_{C}}=\frac{6}{0,421}=14,25 \Rightarrow 14 \text { cycles }
$$

- amount of solution prepared by mixing unit

$$
Q_{l}=N_{C} \cdot Q_{c}=14.1388,16=19434 l
$$

From here the tank volume of the mixing unit can be selected. It is available in two versions volume of $5000 \mathrm{I}$ and $11000 \mathrm{I}$. In order to reduce the number of charges on the mixing unit and the time to move it to the filling station, we select an unit with a tank volume of $11000 \mathrm{I}$. - number of charges of the mixer unit tank for one working shift

$$
n_{m u}=\frac{Q_{l}}{V_{m u}}=\frac{19434}{11000}=1,77 \Rightarrow 2
$$

- number of moves to the place of loading with water and pesticide (without the first one)

$$
N_{m u}=n_{m u}-1=2-1=1
$$

- charging time of the mixing unit

$$
t_{m u}=\frac{V_{m u}}{60 . q_{m u}}=\frac{11000}{60.1000}=0,183 \mathrm{~h},
$$

IRTIIE Vol. 7, No. 3, 2019 ISSN 1314-8788 (print), ISSN 1314-8796 (online), doi: 10.15547/artte.2019.03.001 


\section{ARTTIE $Y$}

Ipplied Resseirlohes in Technics, Technologies ind Bductition

Journal of the Faculty of Technics and Technologies, Trakia University https://sites.google.com/a/trakia-uni.bg/artte/

- $\quad$ time for moving the mixing unit

$$
t_{t m u}=\frac{2 . l_{t}}{v_{t}}=\frac{2.5}{12}=0,833 \mathrm{~h}
$$

- duration of the cycle of the mixing unit

$$
T_{m u}=t_{m u}+t_{t m u}=0,183+0,833=1,016 h
$$

When using the mixing unit with a capacity of $11000 \mathrm{I}$, is required one moving to the place for charging. If immediately after charging the sprayer tank the mixing unit moves to the place for charging, the stoppage of the sprayer after emptying the tank is $1,016-0,421=0,595 \mathrm{~h}$. It can coincide with the time for rest to the operator of the sprayer.

- coefficient of utilization of working time

$$
\tau=\frac{t_{W} \cdot N_{C}}{T_{C} \cdot N_{C}+t_{R}+t_{D}}=\frac{0,386 \cdot 14}{0,421 \cdot 14+1}=0,78
$$

- relative increase of the performance of sprayer

$$
W_{\%}=\frac{t_{C P} \cdot N_{C}}{\left(t_{W}+t_{N}+t_{C W}\right) N_{C}+t_{R}+t_{D}} \cdot 100=\frac{0,17 \cdot 14}{(0,386+0,012+0,023) 14+1} \cdot 100=34,5 \%
$$

It is seen that the coefficient of utilization of working time is considerably higher than that reported in the literature $(0.45-0.55)$ [4]. The performance of the sprayer in the case under consideration is increased by $34.5 \%$. If a mixing unit with a volume of $5000 \mathrm{I}$ is used, the effect on performance will be less. Therefore, using a mixing unit instead of a standard tank for loading the sprayer can significantly improve the efficiency of the process. The calculations here do not take into account the spraying of the headland as its length depends on the area and shape of the field. However, this could not have a significant effect on the result obtained.

When the sprayer is fitted with a mixing vessel located outside the tank, loading with a pesticide is carried out simultaneously with the loading with water. In this case, it may be necessary time only for mixing, but this is performed during movement. With such sprayers, the effect of using a mixed transport unit will be minimal.

\section{CONCLUSIONS}

1. Analytical dependencies have been determined for calculation of various indicators of technological process of the spraying when using a mixing transport unit for preparing the solution and loading the sprayer. Dependence has been obtained to determine the increase in the productivity of the sprayer when loaded with a solution by a mixing unit compared to its loading with water by an ordinary tank with the same parameters.

2. It has been found that the use of a mixing transport unit results in an increase in sprayer productivity by reducing the preparation time of the solution. The use of a mixing unit is particularly effective for sprayers without own mixing vessel outside the tank. For the specific units considered, the sprayer productivity could increase by $34.5 \%$ when loaded with solution instead of pure water. 


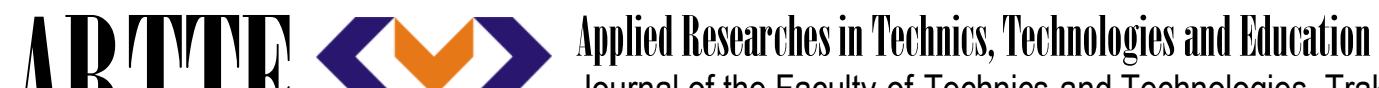 Journal of the Faculty of Technics and Technologies, Trakia University https://sites.google.com/a/trakia-uni.bg/artte/}

\section{REFERENCES}

[1] Dragoev D. \& Kazakova M. (2016). Selection of Machines for Plant Protection, Depending on Their Technical and Technological Parameter. Proceedings of International Conference on Technics, Technologies and Education ICTTE 2016, November 17-18, Yambol, Bulgaria, pp.74-82, [Online]. Available: https://docs.google.com/a/trakiauni.bg/viewer?a=v\&pid=sites\&srcid=dHJha2lhLXVuaS5iZ3xhYWFhfGd4Ojk1NzE4YjliMjc 3YTNmNg [2019-05-14].

[2] Kehayov D. \& Komitov G. (2015). Optimization of the Composition of Machine-Tractor Park for Plant Protection in Agrotrejd EOOD, village of Okop, Yambol. Scientific work of the Russe university - 2015, vol. 54, series 1.1, 131-136

[3] Mixers of Transportation Combinated STK-5, STK-11, [Online]. Available: http://kazansm.ru/smeshivateli-transportirovochnye-kombinirovannye-s/ [2019-05-14].

[4] Trendafilov K. (2012). Handbook on the operation of the machine-tractor park. Publishing House "Trakia University". 